\title{
mtDNA polymorphism and metabolic inhibition affect sperm performance in conplastic mice
}

\author{
Maximiliano Tourmente ${ }^{1}$, Misa Hirose ${ }^{2}$, Saleh Ibrahim², Damian K Dowling ${ }^{3}$, \\ Daniel M Tompkins ${ }^{4}$, Eduardo R S Roldan ${ }^{1}$ and Neil J Gemmell ${ }^{5}$ \\ ${ }^{1}$ Department of Biodiversity and Evolutionary Biology, Museo Nacional de Ciencias Naturales (CSIC), Madrid, \\ Spain, ${ }^{2}$ Institute of Experimental Dermatology, University of Luebeck, Luebeck, Germany, ${ }^{3}$ School of Biological \\ Sciences, Monash University, Clayton, Australia, ${ }^{4}$ Landcare Research, Dunedin, New Zealand and ${ }^{5}$ Department of \\ Anatomy, University of Otago, Dunedin, New Zealand \\ Correspondence should be addressed to N Gemmell; Email: neil.gemmell@otago.ac.nz
}

\begin{abstract}
Whereas a broad link exists between nucleotide substitutions in the mitochondrial genome (mtDNA) and a range of metabolic pathologies, exploration of the effect of specific mtDNA genotypes is on-going. Mitochondrial DNA mutations are of particular relevance for reproductive traits, since they are expected to have profound effects on male specific processes as a result of the strict maternal inheritance of mtDNA. Sperm motility is crucially dependent on ATP in most systems studied. However, the importance of mitochondrial function in the production of the ATP necessary for sperm function remains uncertain. In this study, we test the effect of mtDNA polymorphisms upon mouse sperm performance and bioenergetics by using five conplastic inbred strains that share the same nuclear background while differing in their mitochondrial genomes. We found that, while genetic polymorphisms across distinct mtDNA haplotypes are associated with modification in sperm progressive velocity, this effect is not related to ATP production. Furthermore, there is no association between the number of mtDNA polymorphisms and either (a) the magnitude of sperm performance decrease, or (b) performance response to specific inhibition of the main sperm metabolic pathways. The observed variability between strains may be explained in terms of additive effects of single nucleotide substitutions on mtDNA coding sequences, which have been stabilized through genetic drift in the different laboratory strains. Alternatively, the decreased sperm performance might have arisen from the disruption of the nuclear DNA/mtDNA interactions that have coevolved during the radiation of Mus musculus subspecies.

Reproduction (2017) 154 341-354
\end{abstract}

\section{Introduction}

The mammalian mitochondrial genome (mtDNA) is a closed circular double-stranded DNA molecule that encodes several crucial components of the mitochondrial oxidative phosphorylation (OXPHOS) pathway (Anderson et al. 1981). It is now widely established that mutations in the mtDNA sequence, whether via base substitutions, deletions or insertions, can result in a variety of deleterious effects ranging from discrete disorders through to predispositions to polygenic diseases (Taylor \& Turnbull 2005). However, while the broad link between mtDNA variation and pathology is established, there is still a great deal of work required to more precisely map the link between specific mtDNA genotypes and the organismal phenotype. In particular, the on-going exploration of mtDNA variability, and its effects upon cell physiology, is of significance to a variety of biomedical fields, including studies of metabolic disease, cancer, neurobiology and fertility.
In mice, the most commonly observed functional response to nonsynonymous alterations in mitochondrial DNA is a decline in mitochondrial oxidative phosphorylation (Moreno-Loshuertos et al. 2006), coupled with augmented mitochondrial reactive oxygen species (ROS) production (Yu et al. 2009b, Weiss et al. 2012), decreased ATP levels (Weiss et al. 2012), and the consequent increase in oxidative damage to DNA, proteins and lipids (Cui et al. 2012). Nonetheless, nucleotide polymorphisms in mitochondrial genes encoding for respiratory complex subunits and mitochondrial transference RNAs have resulted in other significant alterations, such as upregulation of respiratory complex activity (Bar et al. 2013, Mayer et al. 2015, Schauer et al. 2015) and expression (Bar et al. 2013), increase of cellular ATP content (Scheffler et al. 2012, Bar et al. 2013, Mayer et al. 2015, Schauer et al. 2015), decreased ROS production (Schauer et al. 2015, Kretzschmar et al. 2016), and disruption of mitochondrial morphology (Weiss et al. 2012). 
These effects on cell metabolic phenotype have been shown to substantially impact the general physiology of organisms, producing symptoms compatible with metabolic syndromes such as diminished hearing (Johnson et al. 2001), impaired spatial navigation (Mayer et al. 2015), increased anxiety-related behavior (Yu et al. 2009a), insulin secretion (Scheffler et al. 2012, Weiss et al. 2012), reduced litter size (Yu et al. 2009b) and increases in the rate of incidence of autoimmune diseases (Yu et al. 2009b), non-alcoholic steatohepatitis (Schroder et al. 2016), Alzheimer's and Parkinson's diseases (Shoffner et al. 1993, van der Walt et al. 2003), multiple sclerosis (Kalman \& Alden 1998) and bipolar disorders (Kato et al. 2001). However, while mtDNA polymorphisms tend to produce phenotypes regarded as deleterious for the organism (see examples above), they may also result in unexpected benefits. For example, nucleotide substitutions in genes coding for respiratory complexes I and IV have been associated with less severe autoimmune encephalomyelitis (Yu et al. 2009a), lower cerebral A $\beta$ amyloid load (Scheffler et al. 2012), resistance to type I diabetes (Mathews et al. 2005), protection against induced colitis (Bar et al. 2013), and reduced tissular senescence (Schauer et al. 2015).

Although the majority of studies linking mtDNA variations to phenotype have been performed in mice (Yu et al. 2009a), there is little work examining their impact on fertility. This is an important area of study because the asymmetry in fitness that arises between males and females as a result of the maternal inheritance of mtDNA (Gemmell et al. 2004) is expected to have profound effects on male specific processes, such as sperm development and function (Gemmell et al. 2004). Recent work in the fruit fly (Drosophila melanogaster) provides empirical support for this asymmetry (Innocenti et al. 2011, Yee et al. 2013, Dowling et al. 2015, Wolff et al. 2016), and there is similar support in mice (Nakada et al. 2006) although this is based on a single mitochondrial mutant line and further work is needed to test the generality of findings.

The motility of mammalian sperm accounts for about $70 \%$ of total sperm ATP consumption (Bohnensack \& Halangk 1986), and relies on ATP production by two main metabolic pathways compartmentalized in different regions of the cell (Ford 2006, Ruiz-Pesini et al. 2007, Storey 2008, Cummins 2009): oxidative phosphorylation (OXPHOS) which occurs in the mitochondria of the sperm midpiece, and anaerobic glycolysis which takes place in the fibrous sheath of the flagellum's principal piece. OXPHOS has been historically regarded as the main source of ATP production for sperm motility (Van Dop et al. 1977, Hammerstedt \& Lardy 1983, Gopalkrishnan et al. 1995, Ferramosca et al. 2008), and remains so in several mammalian species, in which mitochondrial membrane potential and oxygen consumption rate both are positively associated with sperm ATP content and performance (reviewed in
Ford 2006, Pasupuleti 2007, Ruiz-Pesini et al. 2007, Storey 2008).

Sperm motility is crucially dependent on ATP in most animals studied including mice however, the importance of mitochondrial function in producing the ATP needed for sperm function in mouse remains equivocal. While there is evidence suggesting that a fully active glycolytic pathway is essential to sustain sperm motility (Miki et al. 2004, Mukai \& Okuno 2004, Danshina et al. 2010, Nakamura et al. 2013, Odet et al. 2013) and capacitation (Travis et al. 2001, Urner et al. 2001, Tanaka et al. 2004, Goodson et al. 2012, Odet et al. 2013, Tang et al. 2013), numerous experiments show that both glycolysis and OXPHOS are able to sustain vigorous sperm motility in the presence of their specific substrates (Travis et al. 2001, Narisawa et al. 2002, Pasupuleti 2007, Goodson et al. 2012, Odet et al. 2013, Takei et al. 2014). Mouse sperm are able to maintain basal ATP content and progressive motility when treated with uncoupler agents (Goodson et al. 2012, Odet et al. 2013) or respiratory inhibitors (Pasupuleti 2007), in glucose free media. Also, a recent study comparing sperm metabolism between three closely related mouse species found that differences in the OXPHOS vs glycolysis usage ratio were associated with variations in sperm ATP content and performance (Tourmente et al. 2015a).

In this context, while mtDNA polymorphisms resulting from interspecific divergence might account for differences in sperm metabolic phenotype, the confounding effect of divergent nuclear genomes precludes precise comparisons. Furthermore, because mtDNA features numerous unique characteristics in comparison to the nuclear genome, such as an absence of recombination, exclusive maternal inheritance, high number of copies per cell, faster mutation rate and differences in codon usage (Taylor \& Turnbull 2005), the engineering and integration of targeted mutations into the mitochondrial genome remains technically challenging, and relevant mammalian models tend to be scarce (Wallace \& Fan 2009). As a solution to both problems, the naturally occurring and stable mtDNA polymorphisms between common inbred mouse strains (Yu et al. 2009a, Scheffler et al. 2012, Weiss et al. 2012) and closely related mouse subspecies (Yu et al. 2009a) may be used to generate conplastic mouse strains by means of directed backcrossing. These strains carry a common nuclear background and a diversity of mitochondrial genomes, which are useful for the assessment of the effects of polymorphic mtDNA (Yu et al. 2009a,b, Scheffler et al. 2012, Weiss et al. 2012), mitochondrial plasticity (Weiss et al. 2012), and the interactions between nuclear and mitochondrial genomes (BayonaBafaluy et al. 2005, Wallace \& Chalkia 2013), while avoiding the confounding effects of divergence in the nuclear genome. 
In the present study, we compared for the first time the sperm phenotype (numbers, performance and ATP production) across five conplastic inbred mouse strains that share the same nuclear background, but whose mitochondrial genomes belong to (a) the same strain providing the nuclear genome, or (b) strains and subspecies featuring different degrees of mitochondrial divergence (i.e. number of mtDNA polymorphisms). To further assess the impact of mtDNA polymorphisms on sperm metabolism, we also examined whether sperm performance and ATP production of these strains showed different responses to the inhibition of the two main sperm ATP producing pathways (OXPHOS and glycolysis).

\section{Materials and methods}

\section{Chemicals}

The base medium used for all experiments was a modified Tyrode's medium $(\mathrm{mT}-\mathrm{H})(\mathrm{pH}=7.4$, osmolality $=295 \mathrm{mosmol} /$ $\mathrm{kg}$ ) (Shi \& Roldan 1995) consisting of $131.89 \mathrm{mM} \mathrm{NaCl}$ (Sigma, S5886), $2.68 \mathrm{mM} \mathrm{KCl}$ (Sigma, P5405), $0.49 \mathrm{mM} \mathrm{MgCl}_{2} .6 \mathrm{H}_{2} \mathrm{O}$ (BDH, 10149), $0.36 \mathrm{mM} \mathrm{NaH} \mathrm{PO}_{4} \cdot 2 \mathrm{H}_{2} \mathrm{O}$ (Merck, 106345), $5.56 \mathrm{mM}$ glucose (Sigma, G6152), $20 \mathrm{mM}$ HEPES (Sigma, $\mathrm{H} 4034), 1.80 \mathrm{mM} \mathrm{CaCl}$ (BDH, 190464K), $0.02 \mathrm{mM}$ phenol red (Sigma, P0290) and 0.09 mM kanamycin (Sigma, K4000). This medium was supplemented with $4 \mathrm{mg} / \mathrm{mL}$ fatty-acid-free BSA (Sigma, A4503), $20 \mathrm{mM}$ Na lactate (Sigma, L7022) and $0.5 \mathrm{mM}$ Na pyruvate (Sigma, P5280). The compounds added to the $\mathrm{mT}-\mathrm{H}$ medium in the experiments assessing sperm performance under metabolic inhibition were antimycin A (Sigma, A8674), rotenone (Sigma, R8875), oligomycin (Sigma, O4876) and $\mathrm{N}$ oxamate (Sigma, O2751).

\section{Animals and body measurements}

Mouse strains were derived as described by Yu et al. (Yu et al. 2009a). Briefly, females from the mtDNA donor strains were crossed with male C57BL/6J mice, and then the females of the $\mathrm{F} 1$ generation were backcrossed to male $\mathrm{C} 57 \mathrm{BL} / 6$ J. This procedure was performed for at least 21 generations, resulting in conplastic strains that carried the C57BL/6J nuclear genome and the mitochondrial genome from donor strains. The following strains were used for this study:

(a) C57BL/6J-mtC57BL/6J (WT): this strain is a regular C57BL/6J inbred stock (12 generations of inbreeding). Thus, this strain possesses a coevolved nuclear-mitochondrial DNA complement (C57BL/6J). According to Yu et al. (Yu et al. 2009a) the mtDNA sequence of this strain (and those of the majority of the common inbred strains) is highly similar to that of Mus musculus domesticus.

(b) $\mathrm{C} 57 \mathrm{BL} / 6)-\mathrm{mtMA} / \mathrm{MyJ}$ (MA/MY): the mitochondrial genome of this strain belongs to the MA/MyJ inbred strain. The mtDNA sequence of this strain carries 3 amino acid variations, resulting from non-synonymous substitutions in 3 different genes, when compared to that of C57BL/6J (Yu et al. 2009a). (c) C57BL/6J-mtCAST/EiJ (CAST): the mitochondrial genome of this strain belongs to the $M$. musculus castaneus subspecies. The mtDNA sequence of this strain carries 379 amino acid variations when compared to that of C57BL/6) (Yu et al. 2009a).

(d) $\mathrm{C} 57 \mathrm{BL} / 6 \mathrm{~J}-\mathrm{mtPWD} / \mathrm{PhJ}$ (PWD): the mitochondrial genome of this strain belongs to the M. musculus musculus subspecies. The mtDNA sequence of this strain carries 390 amino acid variations when compared to that of $\mathrm{C} 57 \mathrm{BL} / 6$ ] (Yu et al. 2009a).

(e) C57BL/6J-mtMOLF/EiJ (MOLF): the mitochondrial genome of this strain belongs to the $M$. musculus molossinus subspecies. The mtDNA sequence of this strain carries 390 amino acid variations when compared to that of $\mathrm{C} 57 \mathrm{BL} / 6$ ] (Yu et al. 2009a).

Adult males (4 months old) of the five strains were obtained from the breeding facility of the University of Lübeck, Germany. The mice were maintained under standard conditions $(14 \mathrm{~h}$ light-10 h darkness, $22-24^{\circ} \mathrm{C}$ ), with food and water available. Each male was housed in an individual cage for at least two weeks before the experiments took place. Animal handling procedures were performed according to the Spanish Animal Protection Regulation RD53/2013, which conforms to European Union Regulation 2010/63. All procedures in this study were carried out according to guidelines and standards for experimental animals use set by the Spanish Animal Protection Regulation RD53/2013 and European Union Regulation 2010/63. All mouse protocols were approved by the Ethics Committee of the institution's Animal House and the project approved by the Ethics Committee of the Spanish National Research Council (CSIC).

The individuals were euthanized by cervical dislocation, and their body mass $(\mathrm{g})$ and length $(\mathrm{mm})$ were measured testes removal and weighing. Relative testes size (RTS) was estimated by dividing the actual testes mass by the predicted testes mass, obtained from the allometric relation between testes mass and body mass predicted for rodents (Kenagy \& Trombulak 1986): testes mass $=0.031 \times$ body mass 0.77 . Body condition (BC) was estimated as the residual of a linear log-log regression between body length and body mass. These calculations were performed to allow detection of possible biases in sperm quality related to gross testicular development or nutritional status differences between strains.

\section{Sperm collection and incubation}

Mature sperm were collected from the distal portion of the caudae epididymides. The epididymal cauda was excised after removing all blood vessels, fat and surrounding connective tissues, and placed in a Petri dish containing $1 \mathrm{~mL}$ of $\mathrm{mT}-\mathrm{H}$ medium prewarmed to $37^{\circ} \mathrm{C}$. Incisions were performed in the excised cauda and sperm were allowed to swim out for $5 \mathrm{~min}$, after which, the sperm suspension was transferred to a plastic tube. Total sperm numbers were estimated using a modified Neubauer chamber, and sperm concentration was adjusted to $\sim 20 \times 106 \mathrm{sperm} / \mathrm{mL}$ by the further addition of medium.

Sperm parameters (detailed in the following subsection) were assessed immediately after collection (hereafter, 'basal' 
conditions). In order to test the effect of metabolic inhibitors in sperm of the different mouse strains, the sperm suspensions were subsequently divided into 4 aliquots (300 $\mu \mathrm{L}$ per aliquot) and each aliquot received an addition of: (a) culture medium ('control' group), (b) $5 \mu \mathrm{M}$ oligomycin (an inhibitor of the mitochondrial ATP synthase) (Fraser \& Quinn 1981), (c) $1 \mu \mathrm{M}$ antimycin $\mathrm{A}+1 \mu \mathrm{M}$ rotenone (inhibitors of the mitochondrial respiratory complexes III and I respectively) (Gerez de Burgos et al. 1978, Burgos et al. 1982), (d) 30 mM sodium oxamate (an inhibitor of lactate dehydrogenase 4 (LDH4), an enzyme essential for glycolysis) (Odet et al. 2011). After these additions, the sperm suspensions were incubated at $37^{\circ} \mathrm{C}$ under air for $30 \mathrm{~min}$, and sperm parameters were measured.

\section{Sperm motility, velocity and ATP content}

Sperm parameters were assessed in at least 5 males of each strain (6 in the case of WT). The percentage of motile sperm (MOT) was evaluated by examining $10 \mu \mathrm{L}$ of sperm suspension between a pre-warmed slide and a coverslip at $100 \times$ magnification under phase-contrast optics. This parameter was estimated subjectively by at least two independent, experienced observers; estimations from the different observers were averaged and rounded to the nearest $5 \%$ value. Additionally, the quality $(\mathrm{Q})$ of sperm movement was ranked in a scale from 1 to 5 (from least to most vigorous movement). A sperm motility index (SMI) was calculated using the following equation: $\mathrm{SMI}=(\mathrm{Q} \times 20+\mathrm{MOT}) / 2$.

Sperm swimming velocity was assessed by placing an aliquot of sperm suspension in a pre-warmed, microscopy chamber of $20 \mu \mathrm{m}$ depth, (Leja, Nieuw-Vennep, Netherlands). Individual sperm trajectories were recorded using a phasecontrast microscope connected to a digital video camera (Basler A312fc, Vision Technologies, Glen Burnie, MD, USA). The following parameters were estimated for each sperm trajectory using a computer aided sperm analyzer (CASA) (Sperm Class Analyzer, Microptic SL, Barcelona, Spain): curvilinear velocity (VCL, $\mu \mathrm{m} / \mathrm{s})$, straight-line velocity (VSL, $\mu \mathrm{m} / \mathrm{s})$, average path velocity (VAP, $\mu \mathrm{m} / \mathrm{s})$, linearity $(\mathrm{LIN}=\mathrm{VSL} /$ VCL), straightness (STR $=$ VSL/NAP), wobble coefficient $(\mathrm{WOB}=\mathrm{VAP} / \mathrm{VL})$, amplitude of lateral head displacement $(\mathrm{ALH}, \mu \mathrm{m})$, and beat-cross frequency $(\mathrm{BCF}, \mathrm{Hz})$. The final value for each of these parameters was calculated as the mean of all the individual trajectories for each sample. All video captures were manually curated and trajectories corresponding to drifting particles, drifting immotile sperm, sperm that were motile but not progressive (stuck in place), and occasional sperm aggregations, were removed from analysis.

Sperm ATP content was measured using a luciferase-based ATP bioluminescent assay kit (Roche, ATP Bioluminescence Assay Kit HS II) (Tourmente et al. 2015a). A $100 \mu \mathrm{L}$-aliquot of diluted sperm suspension was added to $100 \mu \mathrm{L}$ of Cell Lysis Reagent and incubated at room temperature for $5 \mathrm{~min}$. The resulting cell lysate was centrifuged at 12,000 $\mathrm{g}$ for $2 \mathrm{~min}$, and the supernatant was recovered and frozen in liquid N2. The bioluminescence of the samples was measured in triplicate in 96-well plates using a luminometer (Synergy HT, Biotek Instruments Inc.). Using the auto-injection function, $50 \mu \mathrm{L}$ of luciferase reagent was added to $50 \mu \mathrm{L}$ of sample in each well, and light emission was measured over a $5 \mathrm{~s}$ integration period, after a delay of $1 \mathrm{~s}$. Standard curves were calculated using solutions containing known concentrations of ATP diluted in $\mathrm{mT}-\mathrm{H}$ and Cell Lysis Reagent in a proportion equivalent to that of the samples. ATP content was expressed as amol sperm-1.

\section{Data analysis}

Principal component analyses: Since the sperm trajectory parameters measured by the CASA system tend to be highly correlated (Gomez Montoto et al. 2011b), we summarized these data by performing a principal component analysis (PCA). The loadings and correlation coefficients of each of the eight individual parameters (VCL, VSL, VAP, LIN, STR, WOB, $\mathrm{ALH}$ and $\mathrm{BCF}$ ) with their respective principal components (PCs) are shown in Table 1. The first principal component (PC1) accounted for $68.4 \%$ of the variability of the original parameters, while the second principal component (PC2) accounted for $25.5 \%$. All variables showed a significant positive correlation with PC1, with the exception of ALH for which the correlation was negative. The variables that showed higher loading values and stronger correlation with PC1 (i.e., accounted for the majority of the variability comprised on this axis) were VSL, STR, BCF and LIN. Since all these variables are positively associated with the amount of progressive displacement of a given sperm trajectory, we chose to term PC1 'progressive velocity'. In the case of PC2, five out of the original eight variables (ALH, VCL, WOB, VAP and LIN) were significantly correlated with the component axis. Of these variables, ALH and VCL showed distinctively higher loading values and stronger correlations with the principal component. As these two variables tend to increase in proportion with the amount of lateral displacement on a given sperm trajectory, we termed PC2 'lateral velocity'.

Statistical analyses: Body mass (g), body length (mm), combined testes mass (g), RTS and BC were compared between strains by means of ANOVA with strain as factor, and a posthoc test (Di Rienzo et al. 2002) was used to determine pairwise differences between strains. The same statistical approach was

Table 1 Loadings and correlation of sperm parameters with principal components of sperm velocity and trajectory shape.

\begin{tabular}{lccccc}
\hline & \multicolumn{3}{c}{ PC1 } & & \multicolumn{2}{c}{ PC2 } \\
\cline { 2 - 3 } \cline { 5 - 6 } Variable & Loading & $r$ & & Loading & $r$ \\
\hline VCL & 0.25 & $\mathbf{0 . 5 8}$ & & 0.56 & $\mathbf{0 . 8 0}$ \\
VSL & 0.42 & $\mathbf{0 . 9 8}$ & & 0.13 & 0.19 \\
VAP & 0.37 & $\mathbf{0 . 8 7}$ & & 0.33 & $\mathbf{0 . 4 7}$ \\
LIN & 0.40 & $\mathbf{0 . 9 3}$ & & -0.24 & $-\mathbf{0 . 3 4}$ \\
STR & 0.41 & $\mathbf{0 . 9 5}$ & & -0.10 & -0.15 \\
WOB & 0.33 & $\mathbf{0 . 7 7}$ & & -0.38 & $-\mathbf{0 . 5 4}$ \\
ALH & -0.18 & $-\mathbf{0 . 4 3}$ & & 0.58 & $\mathbf{0 . 8 3}$ \\
BCF & 0.40 & $\mathbf{0 . 9 5}$ & & 0.12 & 0.17 \\
\hline
\end{tabular}

Values presented are Pearson's correlation coefficients. Significant correlation coefficients $(P<0.05)$ are shown in bold.

$\mathrm{ALH}$, amplitude of lateral head displacement $(\mu \mathrm{m}) ; \mathrm{BCF}$, beat-cross frequency $(\mathrm{Hz})$; LIN, linearity $(\mathrm{VSL} / \mathrm{VCL})$; PC1, principal component 1; PC2, principal component 2; STR, straightness (VSL/VAP); VAP, average path velocity $(\mu \mathrm{m} / \mathrm{s}) ; \mathrm{VCL}$, curvilinear velocity $(\mu \mathrm{m} / \mathrm{s}) ; \mathrm{VSL}$, straight-line velocity $(\mu \mathrm{m} / \mathrm{s})$; WOB, wobble coefficient (VAP/VCL). 
used to compare basal values for sperm numbers, motility, SMI, ATP content and sperm velocity principal components.

In order to test the effect of metabolic inhibitors on sperm performance, the values of SMI, ATP content, sperm velocity variables and their summarized principal components were compared for each strain by means of a repeated-measures ANOVA, with treatment as a factor with four levels (control, oligomycin, antimycin + rotenone and oxamate). All variables were log10-transformed, with the exception of the percentage values for MOT, LIN, STR and WOB which were arcsine-transformed. Differences between strains and treatments were compared using Di Rienzo-GuzmánCasanoves (DGC) tests (Di Rienzo et al. 2002). Analyses were performed using InfoStat v.2015p (Grupo Infostat, Universidad Nacional de Córdoba, Córdoba, Argentina) with $\alpha=0.05$.

\section{Results}

\section{Body measurements and basal sperm traits}

The mean values for body measurements, sperm numbers, and basal sperm descriptors for the five conplastic mouse strains analyzed in this study are shown in Table 2. There were no significant differences between strains for body mass $(P=0.1423, F=1.93)$, body length $(P=0.0677, F=2.57)$ and absolute testes mass $(P=0.1058, F=2.18$, Table 2$)$. However, CAST and PWD strains animals had significantly higher RTS $(P=0.0075, F=4.67)$ (Table 2$)$, but this was not associated with increased sperm production since total sperm numbers were not significantly different between strains $(P=0.1409, F=1.94)$ (Table 2$)$.

The percentage of motile cells $(P=0.1116$, $F=2.14)$ and the SMI $(P=0.3916, F=1.08)$ did not vary significantly between strains at basal conditions (Fig. 1A and Table 2). The values obtained for the eight sperm velocity parameters, upon which the PCs were constructed, are summarized in Table 3. When the first principal components for sperm velocity were compared, the WT strain showed a significantly higher progressive velocity $(P=0.0016, F=6.39)$ than the remaining strains (Fig. 1B). Lateral velocity scores were not significantly different between strains $(P=0.6049$, $F=0.69$ ) (Fig. 1C). Finally, sperm ATP content presented similar values between the analyzed strains, with the exception of the PWD strain, which showed significantly lower ATP values $(P=0.0491, F=2.86)$ (Fig. $1 \mathrm{D}$ and Table 2).

\section{Effect of metabolic inhibitors on sperm performance and ATP content}

The inhibition of OXPHOS, by either the oligomycin or antimycin + rotenone treatment, showed no significant effect on the SMI for all strains with the exception of CAST, for which antimycin + rotenone elicited a significant decrease (Fig. 2A and Table 4). ATP levels significantly www.reproduction-online.org

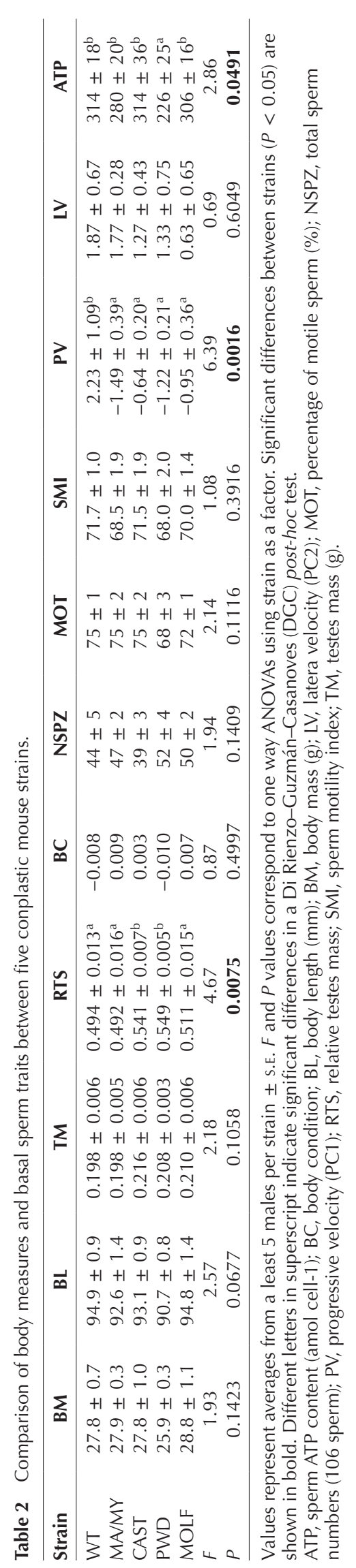

Reproduction (2017) 154 341-354 

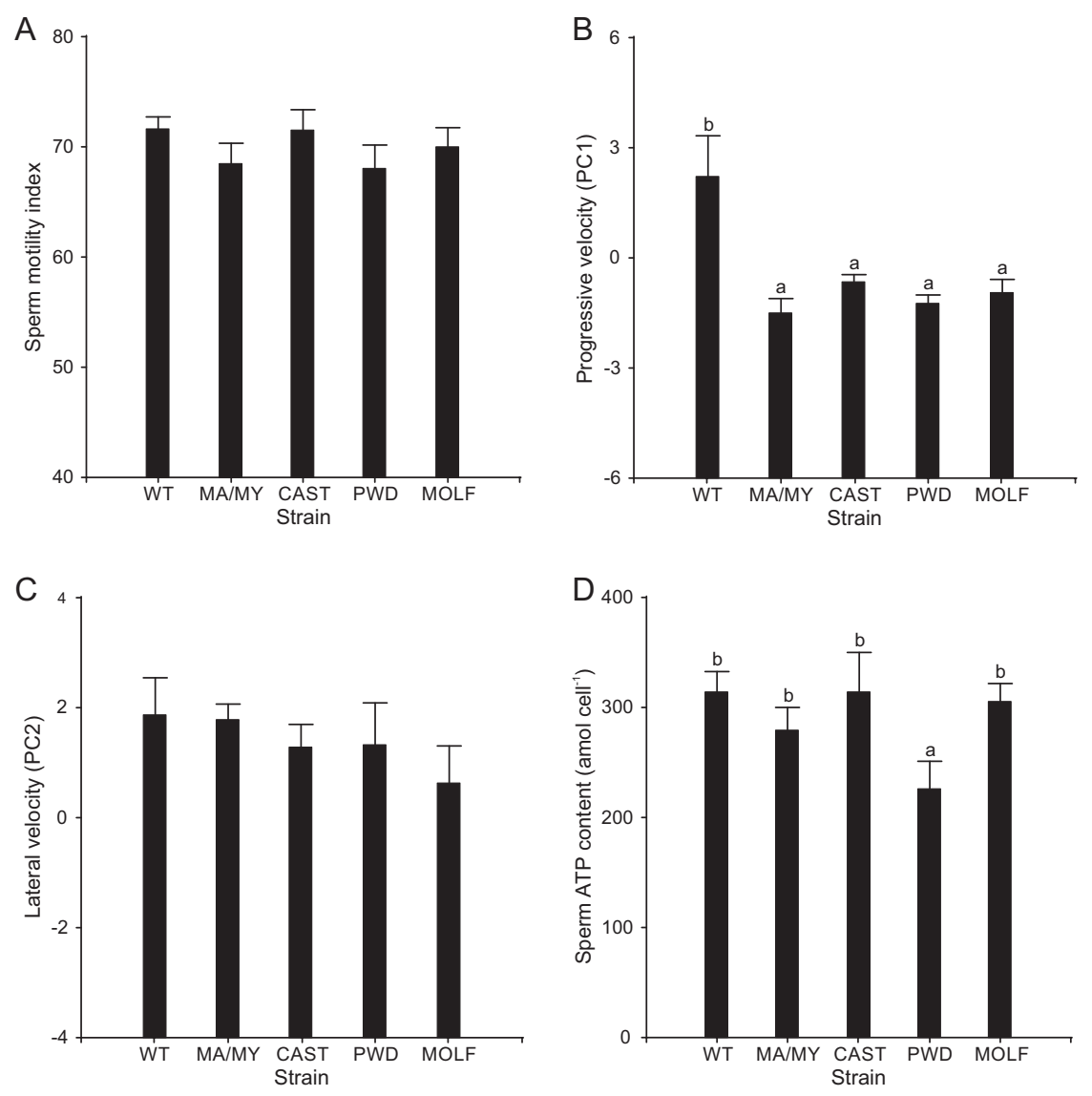

Figure 1 Basal sperm traits in five conplastic
mouse strains. Bars represent averages from a
least 5 males per species, whiskers represent
S.E. (A) Sperm motility index. (B) Progressive
velocity (first principal component of a PCA
using the 8 variables measured by the Sperm
Class Analyzer software). (C) Lateral velocity
(second principal component of a PCA using
the 8 variables measured by the Sperm Class
Analyzer software). (D) Sperm ATP content
(amol cell-1). Different letters indicate
significant differences $(P<0.05$ ) between
species in a parametric DGC post-hoc test.

decreased in response to OXPHOS inhibition in the five strains (Fig. 2B and Table 4).

The effect of OXPHOS inhibition on sperm velocity principal components varied depending on the step of the process that was inhibited. The values of the sperm velocity variables obtained for each strain upon metabolic inhibition are summarized in Table 5. The inhibition of mitochondrial ATP synthase by the addition of $5 \mu \mathrm{M}$ oligomycin significantly decreased sperm progressive velocity in the $\mathrm{WT}, \mathrm{MA} / \mathrm{MY}$ and MOLF strains, but not in the CAST and PWD strains (Fig. 3A and Table 4). The presence of oligomycin also caused a significant increase in sperm lateral velocity in the MA/ MY strain (Fig. 3B and Table 4).

The inhibition of the mitochondrial respiratory chain, by the addition of antimycin (inhibitor of complex III) and rotenone (inhibitor of complex I), significantly decreased sperm progressive velocity in all strains apart from CAST in which this trend was non-significant (Fig. 3A and Table 4). The addition of these inhibitors again also had a significant effect on sperm lateral velocity in the MA/ MY strain (Fig. 3B and Table 4).

Oxamate treatment, inhibiting the key glycolytic enzyme LDH4, had a more severe effect on sperm performance measures than OXPHOS inhibition, significantly reducing SMI in the five strains (Fig. 2A and Table 4). Sperm progressive velocity also decreased significantly in all strains apart from CAST for which the trend was marginally significant (marginally significant) (Fig. 3A and Table 4). Moreover, the decline in progressive velocity promoted by oxamate was higher than that caused by OXPHOS inhibition for the WT, MA/MY and MOLF strains. LDH4 inhibition also promoted a significant increase in sperm lateral velocity for the WT, MA/MY and MOLF strains (Fig. 3B and Table 4). These consistent effects occurred despite significant reduction in ATP content occurring only in WT and MA/MY strains (Fig. 2B and Table 4). Indeed, sperm ATP content was significantly higher under LDH4 inhibition than under OXPHOS inhibition for the WT, CAST, PWD and MOLF strains (Fig. 2B and Table 4).

\section{Discussion}

This study demonstrates clearly (i.e. while controlling for any confounding effects of variation in the nuclear genome) that non-synonymous mutations in the mitochondrial genome result in diminished sperm performance in mice. However, the effects on sperm swimming abilities were not related to ATP production, and there is no clear trend linking the number of mtDNA polymorphisms present with either the intensity of decrease in sperm swimming parameters or the response 


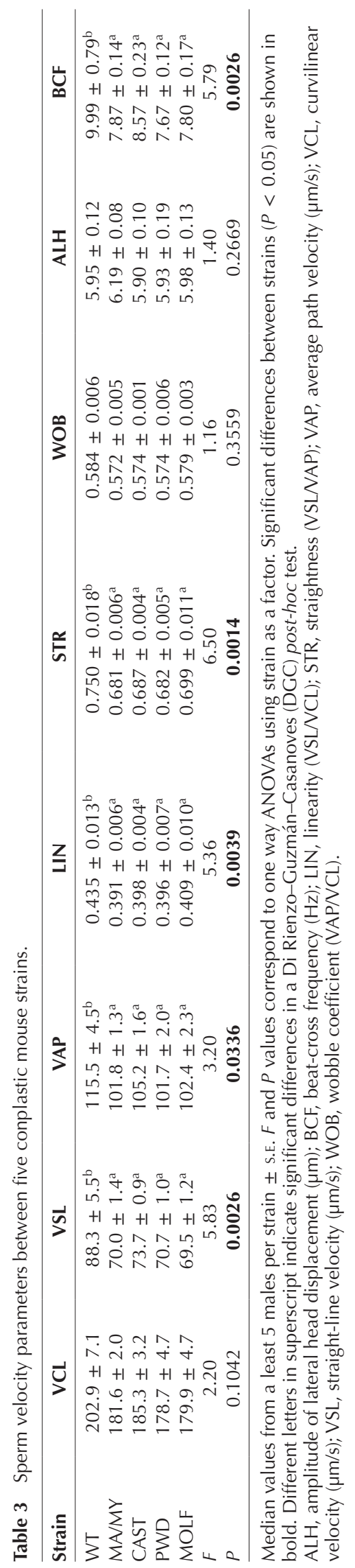

of sperm performance to specific inhibition of the main sperm metabolic pathways.

A clear decrease in sperm swimming performance (progressive velocity) was detected in the conplastic strains (i.e., the strains carrying non-synonymous polymorphisms in their mitochondrial genomes) in comparison to non-conplastic control (i.e., the strain possessing a mitochondrial genome that corresponded to its original nuclear complement). This is in line with previously reported evidence associating single amino acid mutations in mtDNA deletions with decreases in human sperm motility $\left(\mathrm{O}^{\prime}\right.$ Connell et al. 2003, Selvi Rani et al. 2006). However, while numerous studies have reported that nonsynonymous alterations in mtDNA appear to affect cell physiology through a decrease in OXPHOS related ATP production (Trounce et al. 1994, Cui et al. 2012, Weiss et al. 2012, Schroder et al. 2016), we found no such trend. In our study, only the PWD strain had significantly lower sperm ATP content than other conplastic strains (including WT), and this was not associated with differences in sperm velocity or trajectory shape. Furthermore, the higher sperm swimming performance observed for the WT strain was apparently achieved without increased ATP production.

One possible explanation for this discrepancy is that a different mechanism is involved. Recent studies have revealed that particular mtDNA mutations alter mitochondrial morphology (Yu et al. 2009b) and increase ROS production rates (Yu et al. 2009b, Kretzschmar et al. 2016). Such increases can reduce sperm velocity and motility (Moazamian et al. 2015, Ozkosem et al. 2015, 2016) independent of the activities of the respiratory complexes (Yu et al. 2009b) or intracellular ATP levels (Yu et al. 2009b, Kretzschmar et al. 2016). Thus, differing sperm performance among conplastic strains in our study, without related differences in basal ATP levels, may rather be due to differences in intracellular ROS production rates.

Numerous studies analyzing the impact of mtDNA polymorphisms on cell phenotype have focused on disentangling the effects of particular single amino acid mutations (Taylor \& Turnbull 2005, Wallace 2005, Wallace \& Fan 2009, Wallace \& Chalkia 2013). In the case of strains that carry few amino acid substitutions, like the MA/MY strain in our study, mtDNA polymorphisms may be envisioned as discrete agents of physiological alteration that lead to modifications in sperm performance. In particular, the MA/MY strain has three amino acid substitutions located in genes that encode for three different subunits (MT-ND1, MT-ND4L and MT-ND5) of the NADH dehydrogenase (respiratory complex I). Previous research in different cellular models have shown that single nucleotide mutations in these genes tend to be related to reductions in complex I function (Bai et al. 2000, Potluri et al. 2009), and disruption of ROS regulation (Kretzschmar et al. 2016). Furthermore, a study in human sperm associated a single 

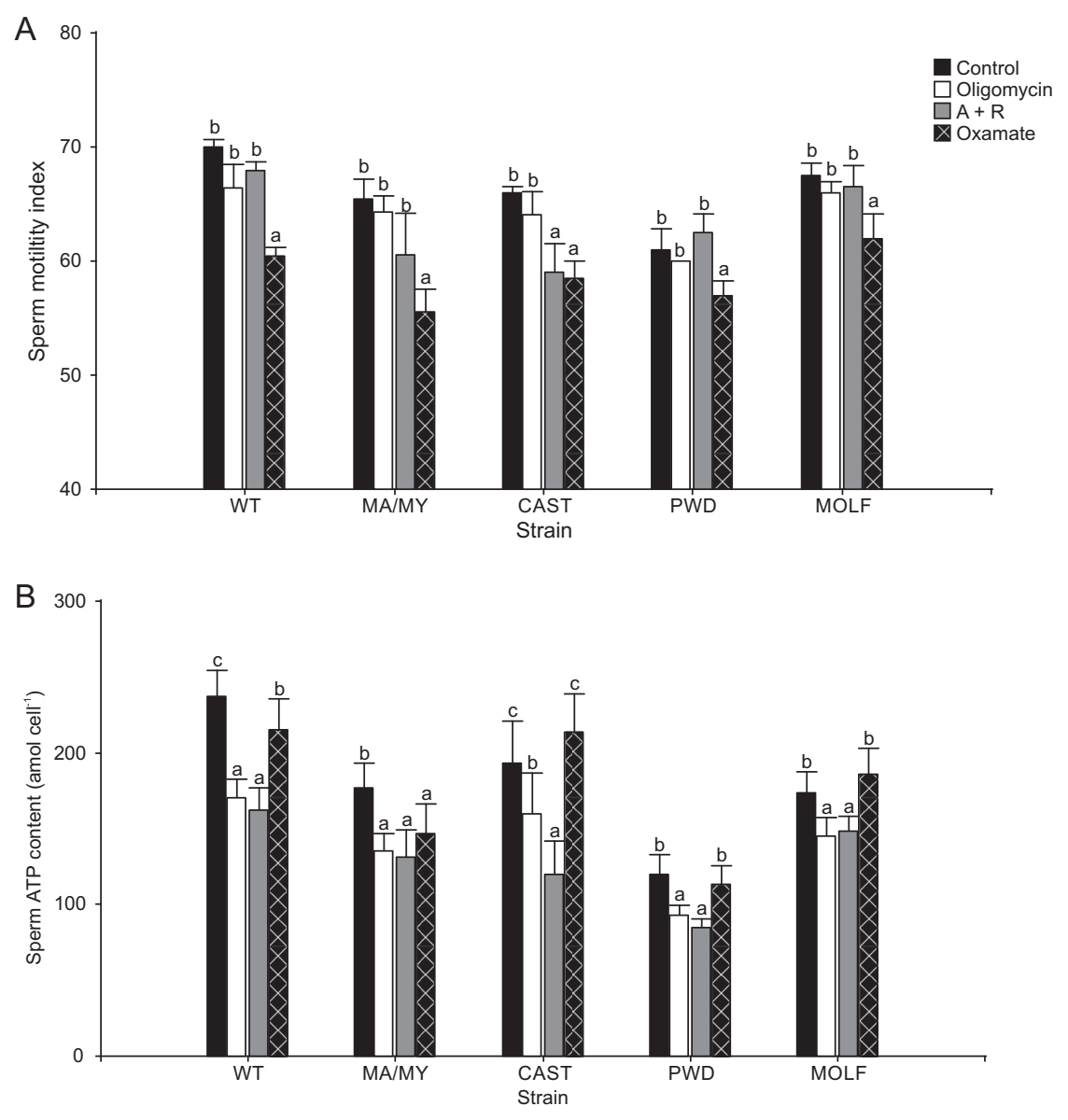

\begin{abstract}
Figure 2 Effect of metabolic inhibitors on sperm motility and ATP content in five conplastic mouse strains. Bars represent averages from a least 5 males per species, whiskers represent SE. (A) Sperm motility index. (B) Sperm ATP content (amol cell-1). Different letters indicate significant differences $(P<0.05)$ between species in a parametric DGC post-hoc test. Black bars: 'Control group' (mT-H added to sperm suspension). White bars: 'Oligomycin group' (5 $\mu \mathrm{M}$ oligomycin added to sperm suspension). Grey bars: 'A + R group' ( $1 \mu \mathrm{M}$ antimycin $\mathrm{A}+1 \mu \mathrm{M}$ rotenone added to sperm suspension. Crossed bars: 'Oxamate group' (30 mM sodium oxamate added to sperm suspension).
\end{abstract}

amino acid mutation in MT-ND4L, albeit on a different position than in MA/MY, to a decrease in human sperm motility (Selvi Rani et al. 2006).

Alternatively, our results may be due to disruption of the adaptive coevolution between nDNA and mtDNA. The other strains used in this study constitute a much higher degree of divergence from the WT strain, having accumulated between 379 (CAST: M. m. castaneus) and 390 (PWD: M. m. musculus, MOLF: M. m. molossinus) single amino acid mutations in their mtDNA during the process of evolutionary radiation from a common M. musculus ancestor. In mammals, the nuclear genome encodes a large number of polypeptides that interact with 13 mitochondrial-encoded polypeptides in order to construct a fully functional OXPHOS pathway, while also providing the biosynthetic apparatus to assemble the proteins of four respiratory complexes (Bayona-Bafaluy et al. 2005). As a consequence of this interaction, both genomes undergo adaptive coevolution in which changes in one of the genomes complement or counterbalance the changes in the other, maintaining the functionality of the OXPHOS chain at adaptive levels (Grossman et al. 2001, Goldberg et al. 2003, RuizPesini et al. 2004). In this context, the creation of new nDNA-mtDNA combinations by crossbreeding between closely related species (Bayona-Bafaluy et al. 2005) and populations (Wallace \& Chalkia 2013) may disrupt this equilibrium by promoting positive feedback mechanisms or additive effects that produce defective phenotypes in complex traits (Roubertoux et al. 2003, Gusdon et al. 2007). Numerous studies have supported this hypothesis by revealing that, stable and functional genetic variations in one genome that do not severely compromise mitochondrial function but confer susceptibility to a disease, may be synergistically aggravated by a polymorphism in the other genome (Mathews et al. 2005, Yu et al. 2009b, Weiss et al. 2012, Schroder et al. 2016). In particular, studies in primates (Grossman et al. 2001, Bayona-Bafaluy et al. 2005) and rodents (Dey et al. 2000, McKenzie \& Trounce 2000) have shown that xenomitochondrial cybrids have reduced activity in multiple respiratory complexes. Additionally, a recent study in D. melanogaster provided evidence that sperm competitiveness was higher when mtDNA haplotypes were expressed alongside a coevolved, rather than evolutionary novel, nuclear genetic background (Yee et al. 2013). Thus, the decrease in sperm performance observed here in conplastic strains that have nuclear and mitochondrial genomes from different subspecies (CAST, PWD and MOLF) might not stem from the accumulation of discrete deleterious effects, but from the disruption of mtDNA-nDNA 
Table 4 Effect of metabolic inhibitors on sperm performance and ATP content in five conplastic mouse strains.

\begin{tabular}{|c|c|c|c|c|c|}
\hline Strain & Treatment & SMI & ATP & PV & LV \\
\hline \multirow[t]{6}{*}{$\overline{W T}$} & Control & $70.0 \pm 0.7^{b}$ & $237 \pm 18^{c}$ & $3.69 \pm 1.19^{d}$ & $0.49 \pm 0.64^{a}$ \\
\hline & Oligomycin & $65.8 \pm 1.5^{b}$ & $170 \pm 12^{\mathrm{a}}$ & $2.89 \pm 0.76^{c}$ & $-0.47 \pm 0.51^{\mathrm{a}}$ \\
\hline & $A+R$ & $67.9 \pm 0.8^{b}$ & $162 \pm 15^{a}$ & $2.04 \pm 0.48^{\mathrm{b}}$ & $-0.02 \pm 0.56^{a}$ \\
\hline & Oxamate & $60.4 \pm 0.8^{\mathrm{a}}$ & $215 \pm 20^{b}$ & $-0.37 \pm 0.77^{a}$ & $1.49 \pm 0.74^{b}$ \\
\hline & $F$ & 22.99 & 34.56 & $\overline{12.46}$ & 9.29 \\
\hline & $P$ & $<0.0001$ & $<0.0001$ & 0.0002 & 0.0010 \\
\hline \multirow[t]{6}{*}{ MA/MY } & Control & $66.0 \pm 1.7^{b}$ & $177 \pm 17^{b}$ & $2.71 \pm 0.63^{d}$ & $-1.35 \pm 0.30^{\mathrm{a}}$ \\
\hline & Oligomycin & $65.0 \pm 1.4^{b}$ & $135 \pm 12^{\mathrm{a}}$ & $0.64 \pm 0.43^{c}$ & $-0.47 \pm 0.30^{b}$ \\
\hline & $A+R$ & $60.5 \pm 3.4^{b}$ & $131 \pm 18^{a}$ & $-0.86 \pm 0.92^{b}$ & $-0.48 \pm 0.29^{b}$ \\
\hline & Oxamate & $55.5 \pm 2.0^{\mathrm{a}}$ & $147 \pm 20^{a}$ & $-3.80 \pm 0.79^{a}$ & $0.67 \pm 0.38^{c}$ \\
\hline & $F$ & $\overline{7} .24$ & 5.88 & 33.05 & 9.57 \\
\hline & $P$ & 0.0050 & 0.0104 & $<0.0001$ & 0.0017 \\
\hline \multirow[t]{6}{*}{ CAST } & Control & $66.5 \pm 0.6^{b}$ & $193 \pm 28^{c}$ & $1.46 \pm 0.36$ & $-0.50 \pm 0.34$ \\
\hline & Oligomycin & $64.0 \pm 1.5^{b}$ & $160 \pm 27^{b}$ & $-0.06 \pm 0.65$ & $-0.48 \pm 0.37$ \\
\hline & $A+R$ & $59.0 \pm 2.6^{\mathrm{a}}$ & $120 \pm 22^{\mathrm{a}}$ & $-1.27 \pm 1.10$ & $-1.47 \pm 0.36$ \\
\hline & Oxamate & $58.5 \pm 1.5^{\mathrm{a}}$ & $214 \pm 25^{c}$ & $-1.65 \pm 0.86$ & $-0.38 \pm 0.38$ \\
\hline & $F$ & 7.49 & 12.42 & 3.45 & 2.78 \\
\hline & $P$ & 0.0044 & 0.0005 & 0.0514 & 0.0867 \\
\hline \multirow[t]{6}{*}{ PWD } & Control & $61.0 \pm 1.9^{b}$ & $120 \pm 13^{b}$ & $0.33 \pm 0.57^{b}$ & $-0.24 \pm 0.62$ \\
\hline & Oligomycin & $60.0 \pm 0.0^{b}$ & $93 \pm 7^{a}$ & $0.32 \pm 0.47^{b}$ & $-1.27 \pm 0.41$ \\
\hline & $A+R$ & $62.5 \pm 1.6^{b}$ & $84 \pm 6^{a}$ & $-1.79 \pm 0.93^{\mathrm{a}}$ & $0.63 \pm 0.45$ \\
\hline & Oxamate & $57.0 \pm 1.2^{\mathrm{a}}$ & $114 \pm 12^{b}$ & $-2.43 \pm 0.38^{\mathrm{a}}$ & $0.30 \pm 0.50$ \\
\hline & $F$ & $\overline{4} .82$ & 13.65 & $\overline{7} .99$ & 2.79 \\
\hline & $P$ & 0.0199 & 0.0004 & 0.0034 & 0.0858 \\
\hline \multirow[t]{6}{*}{ MOLF } & Control & $67.5 \pm 1.1^{\mathrm{b}}$ & $174 \pm 13^{b}$ & $0.96 \pm 0.71^{c}$ & $-1.40 \pm 0.34^{\mathrm{a}}$ \\
\hline & Oligomycin & $66.0 \pm 1.0^{\mathrm{b}}$ & $145 \pm 13^{a}$ & $-0.09 \pm 0.27^{b}$ & $-1.27 \pm 0.28^{a}$ \\
\hline & $A+R$ & $66.5 \pm 1.9^{b}$ & $148 \pm 10^{\mathrm{a}}$ & $-0.50 \pm 0.35^{b}$ & $-1.09 \pm 0.20^{\mathrm{a}}$ \\
\hline & Oxamate & $62.0 \pm 2.1^{\mathrm{a}}$ & $186 \pm 17^{b}$ & $-2.23 \pm 0.57^{\mathrm{a}}$ & $-0.23 \pm 0.28^{b}$ \\
\hline & $F$ & 3.51 & 6.30 & 16.57 & 5.30 \\
\hline & $P$ & 0.0494 & 0.0082 & 0.0001 & 0.0148 \\
\hline
\end{tabular}

Values represent averages from a least 5 males per strain \pm S.E. $F$ and $P$ values correspond to one way repeated-measures ANOVAs using treatment as a factor. Treatments are defined by the addition of either culture medium (Control), $5 \mu \mathrm{M}$ oligomycin (Oligomycin), $1 \mu \mathrm{M}$ antimycin $\mathrm{A}+1 \mu \mathrm{M}$ rotenone $(\mathrm{A}+\mathrm{R}), 30 \mathrm{mM}$ sodium oxamate (Oxamate) to the sperm suspension. Significant differences between strains $(P<0.05)$ are shown in bold. Different letters in superscript indicate significant differences in a Di Rienzo-Guzmán-Casanoves (DGC) post-hoc test.

ATP, sperm ATP content (amol cell-1); LV, lateral velocity (PC2); MOT, percentage of motile sperm (\%); PV, progressive velocity (PC1); SMI, sperm motility index.

adaptive coevolution. Our findings are consistent with this hypothesis since the only strain with coevolved mito-nuclear genotype (WT) generally had higher sperm velocity parameters.

As a further step to elucidate the impact of mtDNA polymorphisms in mouse sperm performance, we tested the effect of metabolic inhibition in sperm motility, swimming velocity and ATP content. The pattern of response of these sperm traits to metabolic inhibition was remarkably similar between strains, showing only a few strain-specific variations in intensity and significance. The intensity of the effect of OXPHOS inhibition on sperm performance was dependent on which step of the process was affected. In general, inhibition of the mitochondrial ATP synthase (by oligomycin) produced a lower decrease in sperm velocity than inhibition of the mitochondrial respiratory chain. A possible explanation of this pattern may be ATP synthase reversal, a common phenomenon in many cellular types (Chen et al. 2014). The decrease of mitochondrial membrane potential associated to the inhibition of the electron transport chain may provoke a reversal in the activity of the F1-F0 ATP synthase, which consumes ATP to deliver protons into the intermembrane space (Ruas et al. 2016). Although this matter has not been yet examined in sperm, ATP synthase inhibition by oligomycin would prevent the reversal of its activity thus avoiding artificial ATP depletion.

Inhibition of the glycolytic pathway (by sodium oxamate) produced a stronger decrease in sperm performance variables than the inhibition of OXPHOS components. Such inhibition caused a significant decrease in the SMI, with slower swimming sperm in four of the five strains and less linear trajectories in three of them. In comparison, OXPHOS inhibition did not significantly decreased sperm motility in general, with only a slight decrease in the CAST strain upon inhibition of the mitochondrial respiratory chain (by antimycin + rotenone). This difference is surprising, since respiratory inhibition promoted a general decrease in sperm ATP content while glycolysis inhibition had a less potent effect (non-significant in 3 of the 5 strains). 


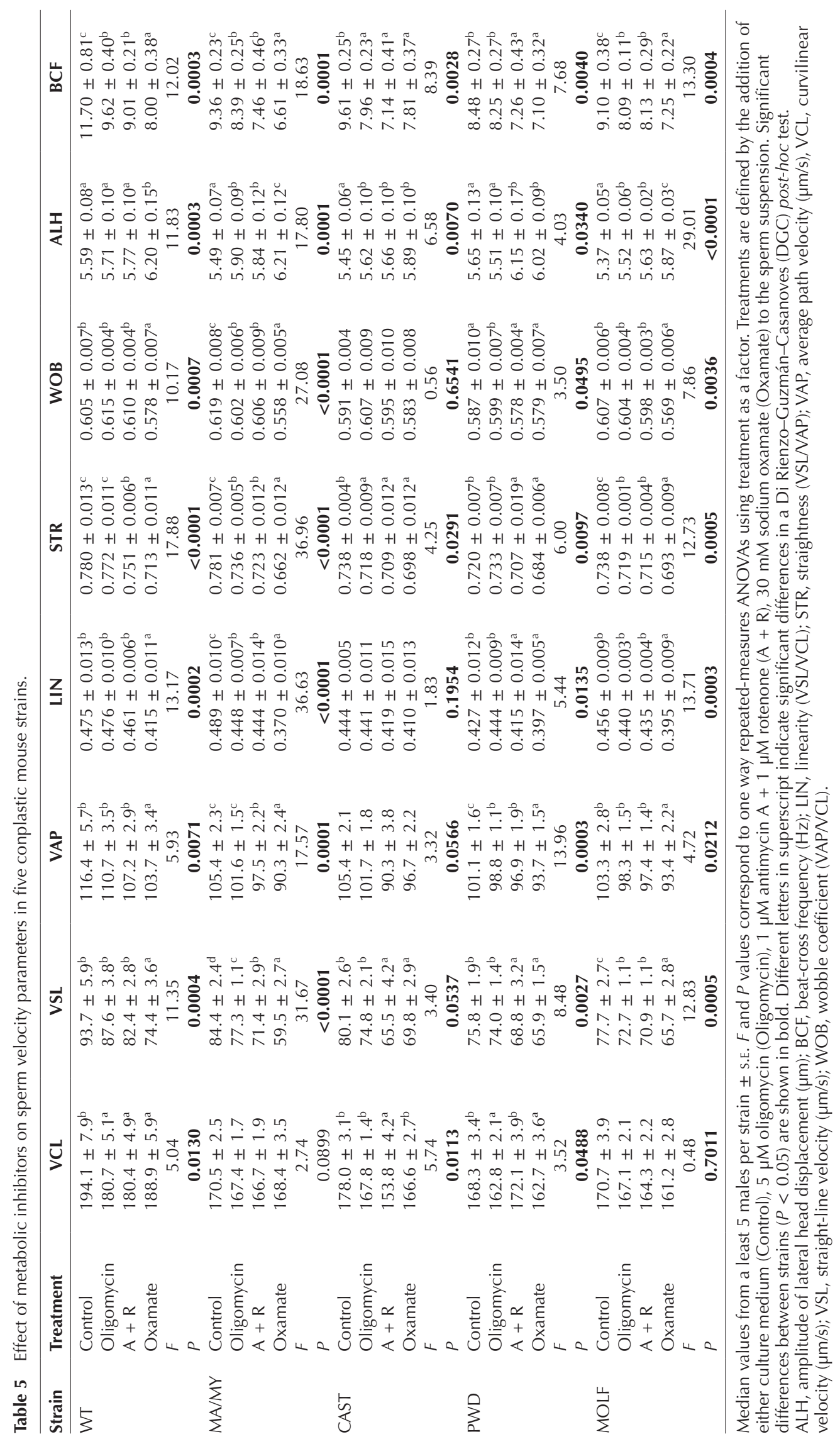




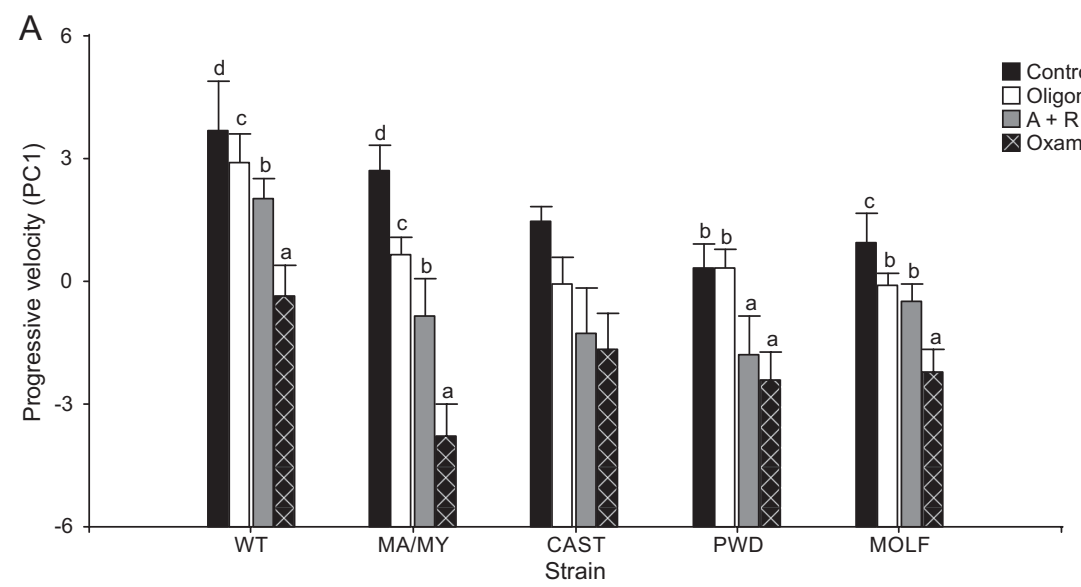

Figure 3 Effect of metabolic inhibitors on sperm velocity. Bars represent averages from a least 5 males per species, whiskers represent S.E. (A) Progressive velocity (first principal component of a PCA using the 8 variables measured by the Sperm Class Analyzer software). (B) Lateral velocity (second principal component of a PCA using the 8 variables measured by the Sperm Class Analyzer software). Different letters indicate significant differences $(P<0.05)$ between species in a parametric DGC post-hoc test. Black bars: 'Control group' (mT-H added to sperm suspension). White bars: 'Oligomycin group' (5 $\mu \mathrm{M}$ oligomycin added to sperm suspension). Grey bars: 'A + R group' ( $1 \mu \mathrm{M}$ antimycin $\mathrm{A}+1 \mu \mathrm{M}$ rotenone added to sperm suspension. Crossed bars: 'Oxamate group' (30 mM sodium oxamate added to sperm suspension).

This suggests that the effect of the inhibition on the glycolytic pathway upon sperm swimming performance is, at least to some extent, independent of its impact on ATP production. Such finding challenges previous studies that suggest glycolysis is the main metabolic pathway sustaining the motility of mouse spermatozoa (Miki et al. 2004, Mukai \& Okuno 2004).

While these results appear to be contradictory, they could be explained by a novel interpretation of the role of glycolysis in sperm flagellum. A recent study analyzing the intraflagellar distribution of adenine nucleotides in mouse sperm showed that glycolysis may act as a spatial ATP buffering system, transferring high energy phosphoryls (ATP) synthesized by mitochondrial OXPHOS from the base of the flagellum to its distal sections (Takei et al. 2014). This is supported by additional evidence that shows mouse sperm can maintain motility using both OXPHOS and glycolysis (Goodson et al. 2012), and that inhibition of glycolysis has a negative impact on sperm motility even in the presence of respiratory substrates (Mukai \& Okuno 2004). In the light of this evidence, our results suggest that glycolysis inhibition would prevent ATP consumption along the flagellum as a consequence of an impairment of ATP transport by glycolytic enzymes. Thus, the observed changes in the pattern of movement and track-shape might be caused by local ATP depletion instead of by a decrease in global intracellular ATP content.

In conclusion, our results revealed that the presence of genetic polymorphisms in the mitochondrial genome is associated with variations of sperm performance in a group of conplastic mouse strains. However, there is no evident pattern of association between the different origin (genetic drift of laboratory strains vs. evolutionary radiation of subspecies) and number of polymorphisms, and the intensity of sperm performance decrease. Furthermore, while the mtDNAmediated differences in sperm performance are likely to be attributable to non-synonymous variation in the mitochondrial genome of the different mouse strains, we cannot map the effects to the level of the SNP, and thus cannot rule out synonymous variation or regulatory variation in the control region of the mtDNA from contributing to the observed phenotypic variations. Moreover, the presence of mtDNA polymorphisms did not promote variation in the general patterns of response of sperm performance upon inhibition of OXPHOS and glycolysis. Since the observed variability may be explained in terms of additive effects of single nucleotide substitutions, or by a disruption of nDNA- 
mtDNA coevolution, a more complete understanding of this phenomenon might be achieved through two different paths: (I) a more detailed description of the effects of the amino acid substitution in mitochondrial and cellular phenotype by creating conplastic strains in which all mtDNA haplotypes derive from the same sub-species, and have arisen under processes of 'mutation-accumulation' in the lab, and (II) an increase in the number of conplastic strains generated from different mouse subspecies and species using a common nuclear background, particularly from species presenting previously identified differences in sperm performance (Gomez Montoto et al. 2011b), quality (Gomez Montoto et al. 2011a) and metabolism (Tourmente et al. 2013, 2015a,b).

\section{Declaration of interest}

The authors declare that there is no conflict of interest that could be perceived as prejudicing the impartiality of the research reported.

\section{Funding}

This work was supported by a Smart Ideas grant from the Ministry of Business, Innovation and Employment (MBIE), New Zealand Government (N J G, D M T and D K D), grants from the Spanish Ministry of Economy and Competitiveness (CGL2011-26341, and CGL2016-80577-P to E R S R) and from the German Science Foundation grant (ExC 306/2 to $\mathrm{MH}$ and $\mathrm{SI})$.

\section{Acknowledgements}

The authors are grateful to the University of Lübeck for developing the conplastic strains and providing the animals. They thank Juan Antonio Rielo for supervising animal facilities and Esperanza Navarro for animal care at the Museo Nacional de Ciencias Naturales in Madrid.

\section{References}

Anderson S, Bankier AT, Barrell BG, de Brujin MHL, Coulson AR, Drouin J, Eperon IC, Nierlich DP, Roe BA, Sanger F et al. 1981 Sequence and organization of the human mitochondrial genome. Nature $\mathbf{2 9 0}$ 457-465. (doi:10.1038/290457a0)

Bai Y, Shakeley RM \& Attardi G 2000 Tight control of respiration by NADH dehydrogenase ND5 subunit gene expression in mouse mitochondria. Molecular and Cellular Biology 20 805-815. (doi:10.1128/ MCB.20.3.805-815.2000)

Bar F, Bochmann W, Widok A, von Medem K, Pagel R, Hirose M, Yu X, Kalies K, Konig P, Bohm R et al. 2013 Mitochondrial gene polymorphisms that protect mice from colitis. Gastroenterology 145 1055-1063. (doi:10.1053/j.gastro.2013.07.015)

Bohnensack R \& Halangk W 1986 Control of respiration and of motility in ejaculated bull spermatozoa. Biochimica et Biophysica Acta 850 72-79. (doi:10.1016/0005-2728(86)90010-1)

Burgos C, Coronel CE, Gerez de Burgos NM, Rovai LE \& Blanco A 1982 Studies in vitro on shuttle systems of mouse spermatozoa. Biochemical Journal 208 413-417. (doi:10.1042/bj2080413)
Cui H, Kong Y \& Zhang H 2012 Oxidative stress, mitochondrial dysfunction, and aging. Journal of Signal Transduction 2012646354. (doi:10.1155/2012/646354)

Cummins JM 2009 Sperm motility and energetics. In Sperm Biology, An Evolutionary Perspective, pp 185-206. Eds T Birkhead, D Hosken \& S Pitnick. San Diego: Academic Press.

Chen WW, Birsoy K, Mihaylova MM, Snitkin H, Stasinski I, Yucel B, Bayraktar EC, Carette JE, Clish CB, Brummelkamp TR et al. 2014 Inhibition of ATPIF1 ameliorates severe mitochondrial respiratory chain dysfunction in mammalian cells. Cell Reports 7 27-34. (doi:10.1016/j. celrep.2014.02.046)

Danshina PV, Geyer CB, Dai Q, Goulding EH, Willis WD, Kitto GB, McCarrey JR, Eddy EM \& O'Brien DA 2010 Phosphoglycerate kinase 2 (PGK2) is essential for sperm function and male fertility in mice. Biology of Reproduction 82 136-145. (doi:10.1095/ biolreprod.109.079699)

Dey R, Barrientos A \& Moraes CT 2000 Functional constraints of nuclearmitochondrial DNA interactions in xenomitochondrial rodent cell lines. Journal of Biological Chemistry 275 31520-31527. (doi:10.1074/jbc. M004053200)

Di Rienzo JA, Guzmán AW \& Casanoves F 2002 A multiple comparisons method based on the distribution of the root node distance of a binary tree. Journal of Agricultural, Biological and Environmental Statistics 7 129-142. (doi:10.1198/10857110260141193)

Dowling DK, Tompkins DM \& Gemmell NJ 2015 The Trojan Female Technique for pest control: a candidate mitochondrial mutation confers low male fertility across diverse nuclear backgrounds in Drosophila melanogaster. Evolutionary Applications 8 871-880. (doi:10.1111/eva.12297)

Ferramosca A, Focarelli R, Piomboni P, Coppola L \& Zara V 2008 Oxygen uptake by mitochondria in demembranated human spermatozoa: a reliable tool for the evaluation of sperm respiratory efficiency. International Journal of Andrology 31 337-345. (doi:10.1111/j.13652605.2007.00775.x)

Ford WC 2006 Glycolysis and sperm motility: does a spoonful of sugar help the flagellum go round? Human Reproduction Update 12 269-274. (doi:10.1093/humupd/dmi053)

Fraser LR \& Quinn PJ 1981 A glycolytic product is obligatory for initiation of the sperm acrosome reaction and whiplash motility required for fertilization in the mouse. Journal of Reproduction and Fertility 61 25-35. (doi:10.1530/jrf.0.0610025)

Gemmell NJ, Metcalf VJ \& Allendorf FW 2004 Mother's curse: the effect of mtDNA on individual fitness and population viability. Trends in Ecology and Evolution 19 238-244. (doi:10.1016/j.tree.2004.02.002)

Gerez de Burgos NM, Burgos C, Montamat EE, Moreno J \& Blanco A 1978 A shuttle system for the transfer of reducing equivalents in mouse sperm mitochondria. Biochemical and Biophysical Research Communications 81 644-649. (doi:10.1016/0006-291X(78)91584-X)

Goldberg A, Wildman DE, Schmidt TR, Huttemann M, Goodman M, Weiss ML \& Grossman LI 2003 Adaptive evolution of cytochrome C oxidase subunit VIII in anthropoid primates. PNAS 100 5873-5878. (doi:10.1073/pnas.0931463100)

Gomez Montoto L, Magana C, Tourmente M, Martin-Coello J, Crespo C, Luque-Larena JJ, Gomendio M \& Roldan ERS 2011 a Sperm competition, sperm numbers and sperm quality in muroid rodents. PLOS ONE 6 e18173. (doi:10.1371/journal.pone.0018173)

Gomez Montoto L, Varea Sanchez M, Tourmente M, Martin-Coello J, Luque-Larena JJ, Gomendio M \& Roldan ERS 2011 b Sperm competition differentially affects swimming velocity and size of spermatozoa from closely related muroid rodents: head first. Reproduction 142 819-830. (doi:10.1530/REP-11-0232)

Goodson SG, Qiu Y, Sutton KA, Xie G, Jia W \& O'Brien DA 2012 Metabolic substrates exhibit differential effects on functional parameters of mouse sperm capacitation. Biology of Reproduction 87 75. (doi:10.1093/ biolreprod/87.s1.75)

Gopalkrishnan K, Padwal V, D'Souza S \& Shah R 1995 Severe asthenozoospermia: a structural and functional study. International Journal of Andrology 18 67-74. (doi:10.1111/j.1365-2605.1995.tb00642.x)

Grossman LI, Schmidt TR, Wildman DE \& Goodman M 2001 Molecular evolution of aerobic energy metabolism in primates. Molecular Phylogenetics and Evolution 18 26-36. (doi:10.1006/mpev.2000.0890)

Gusdon AM, Votyakova TV, Reynolds IJ \& Mathews CE 2007 Nuclear and mitochondrial interaction involving $\mathrm{mt}-\mathrm{Nd} 2$ leads to increased 
mitochondrial reactive oxygen species production. Journal of Biological Chemistry 282 5171-5179. (doi:10.1074/jbc.M609367200)

Hammerstedt RH \& Lardy HA 1983 The effect of substrate cycling on the ATP yield of sperm glycolysis. Journal of Biological Chemistry 258 8759-8768.

Innocenti P, Morrow EH \& Dowling DK 2011 Experimental evidence supports a sex-specific selective sieve in mitochondrial genome evolution. Science 332 845-848. (doi:10.1126/science.1201157)

Johnson KR, Zheng QY, Bykhovskaya Y, Spirina O \& Fischel-Ghodsian N 2001 A nuclear-mitochondrial DNA interaction affecting hearing impairment in mice. Nature Genetics 27 191-194. (doi:10.1038/84831)

Kalman B \& Alden H 1998 Is the mitochondrial DNA involved in determining susceptibility to multiple sclerosis? Acta Neurologica Scandinavica 98 232-237. (doi:10.1111/j.1600-0404.1998.tb07301.x)

Kato T, Kunugi H, Nanko S \& Kato N 2001 Mitochondrial DNA polymorphisms in bipolar disorder. Journal of Affective Disorders 62 151-164. (doi:10.1016/S0165-0327(99)00173-1)

Kenagy GJ \& Trombulak SC 1986 Size and function of mammalian testes in relation to body size. Journal of Mammalogy 67 1-22. (doi:10.2307/1380997)

Kretzschmar C, Roolf C, Timmer K, Sekora A, Knübel G, MuruaEscobar H, Fuellen G, Ibrahim SM, Tiedge M, Baltrusch S et al. 2016 Polymorphisms of the murine mitochondrial ND4, CYTB and COX3 genes impact hematopoiesis during aging. Oncotarget 7 74460-74472. (doi:10.18632/oncotarget.11952)

Mathews CE, Leiter EH, Spirina O, Bykhovskaya Y, Gusdon AM, Ringquist S \& Fischel-Ghodsian N 2005 mt-Nd2 Allele of the ALR/Lt mouse confers resistance against both chemically induced and autoimmune diabetes. Diabetologia 48 261-267. (doi:10.1007/s00125-004-1644-8)

Mayer J, Reichart G, Tokay T, Lange F, Baltrusch S, Junghanss C, Wolkenhauer O, Jaster R, Kunz M, Tiedge M et al. 2015 Reduced adolescent-age spatial learning ability associated with elevated juvenileage superoxide levels in Complex I mouse mutants. PLOS ONE 10 e0123863. (doi:10.1371/journal.pone.0123863)

McKenzie M \& Trounce I 2000 Expression of Rattus norvegicus mtDNA in Mus musculus cells results in multiple respiratory chain defects. Journal of Biological Chemistry 275 31514-31519. (doi:10.1074/jbc. M004070200)

Miki K, Qu W, Goulding EH, Willis WD, Bunch DO, Strader LF, Perreault SD, Eddy EM \& O'Brien DA 2004 Glyceraldehyde 3-phosphate dehydrogenase-S, a sperm-specific glycolytic enzyme, is required for sperm motility and male fertility. PNAS 101 16501-16506. (doi:10.1073/ pnas.0407708101)

Moazamian R, Polhemus A, Connaughton H, Fraser B, Whiting S, Gharagozloo P \& Aitken RJ 2015 Oxidative stress and human spermatozoa: diagnostic and functional significance of aldehydes generated as a result of lipid peroxidation. Molecular Human Reproduction 21 502-515. (doi:10.1093/molehr/gav014)

Moreno-Loshuertos R, Acin-Perez R, Fernandez-Silva P, Movilla N, PerezMartos A, de Cordoba SR, Gallardo ME \& Enriquez JA 2006 Differences in reactive oxygen species production explain the phenotypes associated with common mouse mitochondrial DNA variants. Nature Genetics 38 1261-1268. (doi:10.1038/ng1897)

Mukai C \& Okuno M 2004 Glycolysis plays a major role for adenosine triphosphate supplementation in mouse sperm flagellar movement. Biology of Reproduction 71 540-547. (doi:10.1095/ biolreprod.103.026054)

Nakada K, Sato A, Yoshida K, Morita T, Tanaka H, Inoue S, Yonekawa H \& Hayashi J 2006 Mitochondria-related male infertility. PNAS 103 15148-15153. (doi:10.1073/pnas.0604641103)

Nakamura N, Dai Q, Williams J, Goulding EH, Willis WD, Brown PR \& Eddy EM 2013 Disruption of a spermatogenic cell-specific mouse enolase 4 (eno4) gene causes sperm structural defects and male infertility. Biology of Reproduction $\mathbf{8 8}$ 90. (doi:10.1095/biolreprod.112.107128)

Narisawa S, Hecht NB, Goldberg E, Boatright KM, Reed JC \& Millan JL 2002 Testis-specific cytochrome c-null mice produce functional sperm but undergo early testicular atrophy. Molecular and Cellular Biology 22 5554-5562. (doi:10.1128/MCB.22.15.5554-5562.2002)

O'Connell M, McClure N, Powell LA, Steele EK \& Lewis SEM 2003 Differences in mitochondrial and nuclear DNA status of highdensity and low-density sperm fractions after density centrifugation preparation. Fertility and Sterility 79 754-762. (doi:10.1016/s00150282(02)04827-6)

Odet F, Gabel SA, Williams J, London RE, Goldberg E \& Eddy EM 2011 Lactate dehydrogenase $C$ and energy metabolism in mouse sperm. Biology of Reproduction 85 556-564. (doi:10.1095/biolreprod.111.091546)

Odet F, Gabel S, London RE, Goldberg E \& Eddy EM 2013 Glycolysis and mitochondrial respiration in mouse LDHC-null sperm. Biology of Reproduction 88 95. (doi:10.1095/biolreprod.113.108530)

Ozkosem B, Feinstein SI, Fisher AB \& O'Flaherty C 2015 Advancing age increases sperm chromatin damage and impairs fertility in peroxiredoxin 6 null mice. Redox Biology 5 15-23. (doi:10.1016/j.redox.2015.02.004)

Ozkosem B, Feinstein SI, Fisher AB \& O'Flaherty C 2016 Absence of Peroxiredoxin 6 amplifies the effect of oxidant stress on mobility and SCSA/CMA3 defined chromatin quality and impairs fertilizing ability of mouse apermatozoa. Biology of Reproduction 94 68. (doi:10.1095/ biolreprod.115.137646)

Pasupuleti V Role of glycolysis and representation in sperm metabolism and motility. MsC Thesis 2007. School of Biomedical Sciences, College of Arts and Sciences Kent State University, pp 55.

Potluri P, Davila A, Ruiz-Pesini E, Mishmar D, O'Hearn S, Hancock S, Simon M, Scheffler IE, Wallace DC \& Procaccio V 2009 A novel NDUFA1 mutation leads to a progressive mitochondrial complex I-specific neurodegenerative disease. Molecular Genetics and Metabolism 96 189-195. (doi:10.1016/j.ymgme.2008.12.004)

Roubertoux PL, Sluyter F, Carlier M, Marcet B, Maarouf-Veray F, Cherif C, Marican C, Arrechi P, Godin F, Jamon M et al. 2003 Mitochondrial DNA modifies cognition in interaction with the nuclear genome and age in mice. Nature Genetics 35 65-69. (doi:10.1038/ng1230)

Ruas JS, Siqueira-Santos ES, Amigo I, Rodrigues-Silva E, Kowaltowski AJ \& Castilho RF 2016 Underestimation of the maximal capacity of the mitochondrial electron transport system in oligomycin-treated cells. PLOS ONE 11 e0150967. (doi:10.1371/journal.pone.0150967)

Ruiz-Pesini E, Mishmar D, Brandon M, Procaccio V \& Wallace DC 2004 Effects of purifying and adaptive selection on regional variation in human mtDNA. Science 303 223-226. (doi:10.1126/science.1088434)

Ruiz-Pesini E, Díez-Sánchez C, López-Pérez MJ \& Enríquez JA 2007 The role of the mitochondrion in sperm function: is there a place for oxidative phosphorylation or is this a purely glycolytic process? Current Topics in Developmental Biology 77 3-19. (doi:10.1016/s00702153(06)77001-6)

Schauer M, Kottek T, Schönherr M, Bhattacharya A, Ibrahim SM, Hirose M, Köhling R, Fuellen G, Schmitz U \& Kunz M 2015 A mutation in the NADH-dehydrogenase subunit 2 suppresses fibroblast aging. Oncotarget 6 8552-8566. (doi:10.18632/oncotarget.3298)

Scheffler K, Krohn M, Dunkelmann T, Stenzel J, Miroux B, Ibrahim S, von Bohlen Und Halbach O, Heinze HJ, Walker LC, Gsponer JA et al. 2012 Mitochondrial DNA polymorphisms specifically modify cerebral beta-amyloid proteostasis. Acta Neuropathologica 124 199-208. (doi:10.1007/s00401-012-0980-x)

SchroderT, Kucharczyk D, Bar F, Pagel R, Derer S, Jendrek ST, Sunderhauf A, Brethack AK, Hirose M, Moller S et al. 2016 Mitochondrial gene polymorphisms alter hepatic cellular energy metabolism and aggravate diet-induced non-alcoholic steatohepatitis. Molecular Metabolism $\mathbf{5}$ 283-295. (doi:10.1016/j.molmet.2016.01.010)

Selvi Rani D, Vanniarajan A, Gupta NJ, Chakravarty B, Singh L \& Thangaraj K 2006 A novel missense mutation C11994T in the mitochondrial ND4 gene as a cause of low sperm motility in the Indian subcontinent. Fertility and Sterility 86 1783-1785. (doi:10.1016/j.fertnstert.2006.04.044)

Shi Q \& Roldan ERS 1995 Bicarbonate/ $\mathrm{CO}_{2}$ is not required for zona pellucida- or progesterone-induced acrosomal exocytosis of mouse spermatozoa but is essential for capacitation. Biology of Reproduction 52 540-546. (doi:10.1095/biolreprod52.3.540)

Shoffner JM, Brown MD, Torroni A, Lott MT, Cabell MF, Mirra SS, Beal MF, Yang C-C, Gearing M, Salvo R et al. 1993 Mitochondrial DNA variants observed in Alzheimer disease and Parkinson disease patients. Genomics 17 171-184. (doi:10.1006/geno.1993.1299)

Storey BT 2008 Mammalian sperm metabolism: oxygen and sugar, friend and foe. International Journal of Developmental Biology 52 427-437. (doi:10.1387/ijdb.072522bs)

Takei GL, Miyashiro D, Mukai C \& Okuno M 2014 Glycolysis plays an important role in energy transfer from the base to the distal end of 
the flagellum in mouse sperm. Journal of Experimental Biology 217 1876-1886. (doi:10.1242/jeb.090985)

Tanaka H, Takahashi T, Iguchi N, Kitamura K, Miyagawa Y, Tsujimura A, Matsumiya K, Okuyama A \& Nishimune Y 2004 Ketone bodies could support the motility but not the acrosome reaction of mouse sperm. International Journal of Andrology 27 172-177. (doi:10.1111/j.13652605.2004.00471.x)

Tang H, Duan C, Bleher R \& Goldberg E 2013 Human lactate dehydrogenase A (LDHA) rescues mouse Ldhc-null sperm function. Biology of Reproduction 88 96. (doi:10.1095/biolreprod.112.107011)

Taylor RW \& Turnbull DM 2005 Mitochondrial DNA mutations in human disease. Nature Reviews Genetics 6 389-402. (doi:10.1038/nrg1606)

Tourmente M, Rowe M, González-Barroso MM, Rial E, Gomendio M \& Roldan ERS 2013 Postcopulatory sexual selection increases ATP content in rodent spermatozoa. Evolution 67 1838-1846. (doi:10.1111/evo.12079)

Tourmente M, Villar-Moya P, Rial E \& Roldan ERS 2015a Differences in ATP generation via glycolysis and oxidative phosphorylation and relationships with sperm motility in mouse Species. Journal of Biological Chemistry 290 20613-20626. (doi:10.1074/jbc.M115.664813)

Tourmente M, Villar-Moya P, Varea-Sanchez M, Luque-Larena JJ, Rial E \& Roldan ERS 2015b Performance of rodent spermatozoa over time is enhanced by increased ATP concentrations: the role of sperm competition. Biology of Reproduction 93 64. (doi:10.1095/biolreprod.114.127621)

Travis AJ, Jorgez CJ, Merdiushev T, Jones BH, Dess DM, Diaz-Cueto L, Storey BT, Kopf GS \& Moss SB 2001 Functional relationships between capacitation-dependent cell signaling and compartmentalized metabolic pathways in murine spermatozoa. Journal of Biological Chemistry 276 7630-7636. (doi:10.1074/jbc.M006217200)

Trounce I, Neill S \& Wallace DC 1994 Cytoplasmic transfer of the mtDNA nt 8993 T-->G (ATP6) point mutation associated with Leigh syndrome into mtDNA-less cells demonstrates cosegregation with a decrease in state III respiration and ADP/O ratio. PNAS 91 8334-8338. (doi:10.1073/ pnas.91.18.8334)

Urner F, Leppens-Luisier G \& Sakkas D 2001 Protein tyrosine phosphorylation in sperm during gamete interaction in the mouse: the influence of glucose. Biology of Reproduction 64 1350-1357. (doi:10.1095/biolreprod64.5.1350)

Van Dop C, Hutson SM \& Lardy HA 1977 Pyruvate metabolism in bovine epididymal spermatozoa. Journal of Biological Chemistry 252 1303-1308.

van der Walt JM, Nicodemus KK, Martin ER, Scott WK, Nance MA, Watts RL, Hubble JP, Haines JL, Koller WC, Lyons K et al 2003 Mitochondrial polymorphisms significantly reduce the risk of Parkinson disease. American Journal of Human Genetics 72 804-811. (doi:10.1086/373937)

Wallace DC 2005 A mitochondrial paradigm of metabolic and degenerative diseases, aging, and cancer: a dawn for evolutionary medicine. Annual Review of Genetics 39 350-407. (doi:10.1146/ annurev.genet.39.110304.095751)

Wallace DC \& Fan W 2009 The pathophysiology of mitochondrial disease as modeled in the mouse. Genes and Development 23 1714-1736. (doi:10.1101/gad.1784909)

Wallace DC \& Chalkia D 2013 Mitochondrial DNA genetics and the heteroplasmy conundrum in evolution and disease. Cold Spring Harbor Perspectives in Biology 5 a021220. (doi:10.1101/cshperspect.a021220)

Weiss H, Wester-Rosenloef L, Koch C, Koch F, Baltrusch S, Tiedge M \& Ibrahim S 2012 The mitochondrial Atp8 mutation induces mitochondrial ROS generation, secretory dysfunction, and beta-cell mass adaptation in conplastic B6-mtFVB mice. Endocrinology 153 4666-4676. (doi:10.1210/en.2012-1296)

Wolff JN, Tompkins DM, Gemmell NJ \& Dowling DK 2016 Mitonuclear interactions, mtDNA-mediated thermal plasticity, and implications for the Trojan Female Technique for pest control. Scientific Reports 630016. (doi:10.1038/srep30016)

Yee WK, Sutton KL \& Dowling DK 2013 In vivo male fertility is affected by naturally occurring mitochondrial haplotypes. Current Biology 23 R55-R56. (doi:10.1016/j.cub.2012.12.002)

Yu X, Gimsa U, Wester-Rosenlof L, Kanitz E, Otten W, Kunz M \& Ibrahim SM 2009a Dissecting the effects of mtDNA variations on complex traits using mouse conplastic strains. Genome Research 19 159-165. (doi:10.1101/gr.078865.108)

Yu X, Wester-Rosenlof L, Gimsa U, Holzhueter SA, Marques A, Jonas L, Hagenow K, Kunz M, Nizze H, Tiedge M et al. 2009b The mtDNA nt7778 $\mathrm{G} / \mathrm{T}$ polymorphism affects autoimmune diseases and reproductive performance in the mouse. Human Molecular Genetics 18 4689-4698. (doi:10.1093/hmg/ddp432)

Received 17 April 2017

First decision 18 May 2017

Revised manuscript received 23 June 2017

Accepted 4 July 2017 